\title{
The Neuro Clinic: A Pilot Model to Facilitate Student Clinical Development through In-Class Patient Experiences while Meeting Community Need
}

Rosanne M. Thomas

Mount St. Joseph University, rosanne.thomas@msj.edu

Jamie Bayliss

Mount St. Joseph University, jamie.bayliss@msj.edu

Follow this and additional works at: https://nsuworks.nova.edu/ijahsp

Part of the Rehabilitation and Therapy Commons

\section{Recommended Citation}

Thomas RM, Bayliss J. The Neuro Clinic: A Pilot Model to Facilitate Student Clinical Development through In-Class Patient Experiences while Meeting Community Need. The Internet Journal of Allied Health Sciences and Practice. 2018 Jan 01;16(1), Article 2.

This Manuscript is brought to you for free and open access by the College of Health Care Sciences at NSUWorks. It has been accepted for inclusion in Internet Journal of Allied Health Sciences and Practice by an authorized editor of NSUWorks. For more information, please contact nsuworks@nova.edu. 


\title{
The Neuro Clinic: A Pilot Model to Facilitate Student Clinical Development through In-Class Patient Experiences while Meeting Community Need
}

\begin{abstract}
Purpose: To detail the implementation and assessment of a pilot model the Neuro Clinic. This is one component of a Patient Experience Model (PEM) of embedded progressive in-class patient experiences (ICPE) in a Doctor of Physical Therapy program. The Patient Experience Model, an innovative model of experiential learning, was developed to bridge the gap between didactic coursework and clinical education, facilitate progressive patient experiences and assess developing student professional and skill competence.

Methods: The Neuro Clinic was held in laboratory classroom space for six weekly sessions with consistent student: patient triads. Overwhelming patient interest indicated a need in our community for such services. With faculty and clinician oversight, second year doctor of physical therapy students conducted an initial examination, developed a plan of care and administrated goal directed activities and exercises that they documented for a medical record. Surveys were conducted with the patient volunteers, the students and the supervising clinicians.

Results: All student documentation and final patient surveys indicated functional and physical improvement. Patient volunteer survey responses consistently indicated the experience met and exceeded expectations. Student survey responses for self-assessment and Clinic logistics, supervision and feedback were positive and detailed.

Conclusion: The Neuro Clinic implementation gave students a way to advance tangible clinical skills and intangible social and professional skills, faculty the means to guide students while bridging the gap between didactic education and clinical application, and addressed community need. This pilot model may be useful to other healthcare programs in their quest to enhance student learning in a way that also benefits multiple constituencies. The Neuro Clinic required minimal resources and was a very positive experience for patients, students and faculty/clinicians. While advancing student development, it fulfilled a service mission congruent to the University.
\end{abstract}

\section{Author Bio(s)}

Rosanne Thomas, PT, PhD is Chair and Associate Professor in the Department of Physical Therapy in the School of Health Sciences at Mount St. Joseph University in Cincinnati Ohio. She has extensive experience incorporating experiential learning in her coursework involving neurological examination and interventions.

Jamie Bayliss,PT, DHSc is Director of Clinical Education and Assistant Professor in the Department of Physical Therapy in the School of Health Sciences at Mount St. Joseph University in Cincinnati Ohio. 


\title{
IJAHSP \\ The Internet Joumnal of Allied Health Sciences and Practice \\ Dedicated to allied health professional practice and education
}

Vol. 16 No. 1 ISSN 1540-580X

\section{The Neuro Clinic: A Pilot Model to Facilitate Student Clinical Development through In-Class Patient Experiences while Meeting Community Need}

\author{
Rosanne M. Thomas, PT, PhD \\ Jamie Bayliss, PT, DHSc \\ Mount St. Joseph University \\ United States
}

\begin{abstract}
Purpose: To detail the implementation and assessment of a pilot model of the Neuro Clinic. This is one component of a Patient Experience Model (PEM) of embedded progressive in-class patient experiences (ICPE) in a Doctor of Physical Therapy program. The PEM, an innovative model of experiential learning, was developed to bridge the gap between didactic coursework and clinical education, facilitate progressive patient experiences, and assess developing student professional and skill competence. Methods: The Neuro Clinic was held in laboratory classroom space for six weekly sessions with consistent student: patient triads. Overwhelming patient interest indicated a need in the community for such services. With faculty and clinician oversight, second year doctor of physical therapy students conducted an initial examination, developed a plan of care, and administrated goal directed activities and exercises that they documented for a medical record. Surveys were conducted with the patient volunteers, the students, and the supervising clinicians. Results: All student documentation and final patient surveys indicated functional and physical improvement. Patient volunteer survey responses consistently indicated the experience met and exceeded expectations. Student survey responses for self-assessment and clinic logistics, supervision, and feedback were positive and detailed. Conclusion: Implementation of the Neuro Clinic gave students a way to advance tangible clinical skills and intangible social and professional skills, faculty the means to guide students while bridging the gap between didactic education and clinical application, and the community a needed service. This pilot model may be useful to other healthcare programs in their quest to enhance student learning in a way that also benefits multiple constituencies. The Neuro Clinic required minimal resources and was a very positive experience for patients, students, and faculty/clinicians. While advancing student development, it fulfilled a service mission congruent to the University.
\end{abstract}

\section{INTRODUCTION}

The challenges of graduating competent, autonomous healthcare practitioners has resulted in numerous models of education with highly variable methods of delivering didactic and clinical education. In Physical Therapy curricula, accreditation standards allow for variability in design while demanding outcome measure uniformity. ${ }^{1}$ Research has indicated that no single Clinical Education (CE) model is superior to another in obtaining favorable outcomes in Doctor of Physical Therapy (DPT) programs. ${ }^{2}$ Likewise, no studies have been identified that indicate a superior curricular model. It is likely that the variety of curricular models allows for complex matching with student preference of learning styles and program uniqueness that appeals to a diverse population.

\section{Identified Need}

Consistent with national trends and in an effort to accommodate the overburdened DPT CE system, Mount St Joseph University's (MSJ) DPT program adopted a model of terminal internships in 2011.3.5 With the exception of two, 2-week Integrated Clinical Experiences (ICE) with large observational components after the first program year, this curricular model had limited patient interactions until the final year when students were immersed in full-time clinical practice for 38 weeks in 4 different clinical internships. Since students often report enhanced learning through direct patient interaction and important professional behaviors are often developed through these experiences, we determined a need to provide significant patient interactions within the didactic portion of the program outside of the standard CE model. Our standard CE model contains 38 weeks of terminal 
clinical internships and are already beyond the Commission on Accreditation in Physical Therapy Education (CAPTE) required 30 weeks. ${ }^{6}$ The addition of in-class patient experiences (ICPE) would allow core faculty to be instrumental in student clinical and professional development with patients while accurately assessing knowledge and skills the student should demonstrate at various curricular points.

We hypothesized that strategic and progressive student-patient interaction would give students confidence and ease in these interactions proactively in preparation for their terminal clinical internships. ${ }^{5}$ Though there is evidence in the literature regarding the value of experiential learning including specifically utilizing patient interactions, we sought to implement and assess the purposeful and progressive integration of patient experiences within the classroom setting with congruent faculty supervision and facilitation. ${ }^{7,8}$ We believe this to be a novel paradigm. Patient volunteers have been recruited to participate in didactic courses in a variety of capacities dependent on the students' developmental level and competency. These experiences, designed to bridge the classroom and clinic, ranged from patient panels discussing implications of living with their diagnosis, to history taking sessions, to very short-term examination sessions with home exercise program (HEP) recommendations, to multisession patient management. These ICPE were progressive in complexity and expectations as students advanced through the program. In addition, patient volunteers could choose their level of participation with many indirectly benefiting from extended sessions with students in later ICPE opportunities.

Students' positive feedback and continued request for more patient interactions along with faculty's desire to assess students' professional development, clinical skill level, and readiness for terminal internships led us to develop a systematic and structured ICPE throughout the entire curriculum. Our Patient Experience Model (PEM) is unique and progressive in nature, intentionally providing students with patient experiences that link application with concurrent didactic instruction without the potential negative real world consequences inherent in revenue-generating clinics. The PEM gives students a safe environment for experiential learning while allowing the experiences to build on each other, providing a structure for the student to prepare for the complex clinical environment.

PEM in year two aims at achieving progressively higher integrative function in three areas: 1) adaptive, professional communication with other healthcare providers, patients, and patient families, 2) emergence of clinical decision-making competency, and 3) development of team leadership. This is accomplished following the same basic tenets outlined for year one, however, all experiences are designed for progressive and varied complexity, requiring progressive mastery of concepts and skills. Additionally, for the most part, student groups are smaller (paired experiences) and require interaction with faculty, other health care providers, and patient family members. Year two encounters carry progressive weight on practice management, course grades, and foster less reliance on faculty guidance (e.g. increased self and team reliance). Since these later experiences typically involved multiple sessions with a patient volunteer/ student partnership, the potential for benefit to the patient volunteer increases.

The purpose of this report is to describe one portion of our PEM; the Neuro Clinic, which is an experience embedded in the second of two neurological rehabilitation courses in the second program year (Figure 1A). In this report, we will detail the creation, implementation, and assessment of the Neuro Clinic, and articulate planned next steps. We will encourage the feasibility of implementation for other healthcare professional programs. 


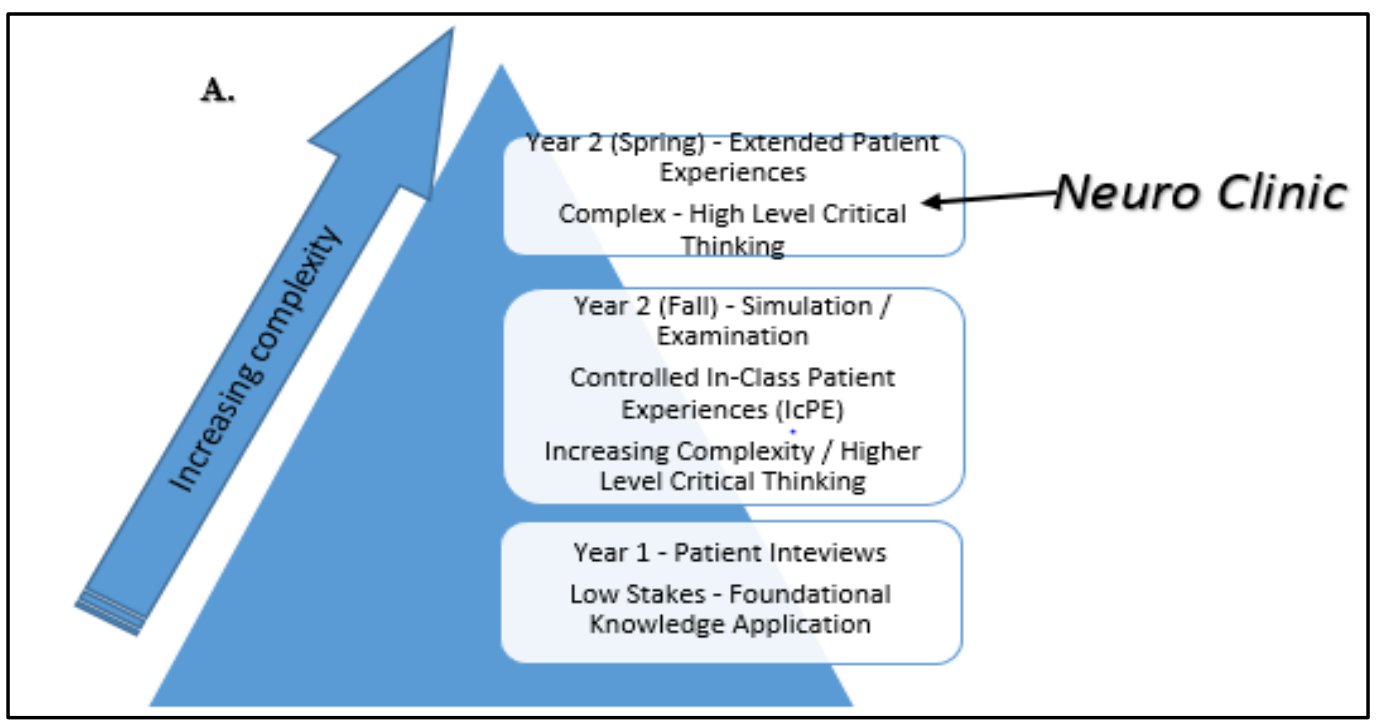

Figure 1 Neuro Clinic Schematic: A. Progressive Integrated Patient Experiences (PEM)

\section{Patient Experience Model Development/ Background}

Mount St Joseph University, a small private institution founded on the beliefs of the Sisters of Charity in Cincinnati $\mathrm{OH}$, has faced budgetary and resource challenges common to such small institutions in recent years. Keeping with the service-oriented mission of our institution and aware of the need for fiscal responsibility, the DPT program determined to develop low cost, in-depth, and progressive experiential learning opportunities for their students that would impact student development as well as provide services to underserved community populations.

The Neuro Clinic was strategically placed after students had completed one semester of instruction in basic neurological diagnoses, their medical management, and basic physical therapy management of these conditions in Neurological Rehabilitation I. During this first Neuro Rehab course, students were given controlled IcPE in which they worked in groups of four to examine a patient volunteer with the corresponding neurological diagnosis studied in class, identify problems, goals, and interventions to address functional deficits, and document their initial findings. Students received extensive supervision and feedback from faculty. As indicated by student course evaluations, these brief patient interactions in Neuro Rehab I were often the first interaction students had with patients with the multiple impairments and functional limitations common to those with neurological diagnoses. This was also students' first opportunity to see and feel common neurological deficits such as hypertonicity and ataxic movement patterns; concepts difficult to illustrate in typical coursework. These experiences were highly valued by the students as noted in course evaluations. Thus, the Neuro Clinic in Neuro Rehab II came after these foundational patient experiences.

The Neuro Clinic, strategically placed in Neuro Rehab II during the end of the student's second program year, was worth $15 \%$ of the course grade and ran for six weekly sessions with a consistent student-patient triad. Each session was structured with prescribed components as illustrated in Figure 1B and Table 1. All sessions included student submission of appropriate documentation including initial examination, weekly progress notes, re-assessment, and discharge notes. Documentation folders were kept secured and confidential in a locked file cabinet on-site. Since these experiences were classified as learning experiences within coursework, documentation was not deemed as individual patient volunteer information and storage was compliant with all institutional and federal privacy regulations. Documentation was reviewed weekly by the course instructor with student groups given written and verbal feedback that often lead to student revision of documentation, especially in initial weeks. Most weeks also included some type of assessment or activity related to that week's class content. For example, in the third week, students developed and implemented a fitness plan with their patient after learning about fitness in the neurological population. In week four, students assessed their integration of neuroplasticity concepts into their treatment approach with their assigned patient. 


\begin{tabular}{|l|l|}
\hline B. Student Responsibilities for the Neuro Clinic & C. Grading Criteria \\
\hline 1. Comprehensive PT examination with documentation & 1. Progression of patient intervention and education \\
\hline 2. Development of a problem list and functional goals & 2. Timeliness and accuracy of documentation \\
\hline 3. Establishment of a treatment plan & 3. Facilitation of group function \\
\hline 4. Implementation and modification of the treatment plan & 4. Flexibility with patient needs and scheduling \\
\hline 5. Documentation of daily PT interventions with a SOAP* note & 5. Clinic set up and tear down \\
\hline 6. Mid-term Re-evaluation and Re-assessment of goals & 6. Peer assessment \\
\hline 7. Patient education including a home exercise program & \\
\hline $\begin{array}{l}\text { 8. PT discharge examination and functional status with } \\
\text { documentation }\end{array}$ & \\
\hline
\end{tabular}

PT= physical therapy, SOAP= Subjective, Objective, Assessment, Plan

Patient volunteers were recruited via flyers that articulated the process and participation expectations. These flyers were electronically distributed to the University community as well as local senior facilities, rehabilitation facilities, clinical instructors, external advisory board members, and diagnosis specific support groups. Patient interest was overwhelming and unexpected, resulting in a wait list and indicating a possible need for services to the neurological patient population in our community. Many patient volunteers, while registering for the Clinic, reported no longer qualifying for skilled services while still desiring improved functional abilities. Initial patient profiles included Multiple Sclerosis (MS), Stroke, Parkinson's disease (PD), and glioblastoma. Upon patient registration as a volunteer, each individual was sent a welcome packet including a consent form and an intake form for general information such as past medical history, medications, physician contact information, details about neurological diagnosis, and goals for their participation. Patient volunteers signed a consent form for participation and videotaping indicating understanding of their volunteer status for learning purposes. All completed forms were securely kept with student documentation for each visit as previously described. One patient dropped out after 3 weeks due to transportation issues. All other patients completed the entire Neuro Clinic.

Patient complexity was varied both within diagnoses and across diagnoses with some patients requiring moderate to maximum assistance and some patients independent but inefficient with basic functional activities. Students were encouraged to observe other patients with different functional levels and diagnoses when they were not treating their patient. If a patient cancelled a session, those students were assigned to assist another group with a patient at a different functional level.

Supervision for each session was ongoing with two core faculty and three additional community physical therapists who all had experience as American Physical Therapy Association credentialed Clinical Instructors. Supervisors were trained to answer questions, facilitate clinical decision making, provide feedback when approached by students, and to encourage student autonomy within a safe practice environment.

The clinic was held in laboratory classroom space that, with rearrangement, was able to easily house treatment stations for up to eight patients at a time, supplying a treatment mat table, stationary chair, and rolling stools for each station as well as typical clinical equipment found in a clinic treating patients with neurological disorders. Equipment needs were met with items on-hand prior to clinic implementation, keeping costs minimized and utilizing equipment often only used for demonstration purposes. Student-patient triads were rotated through the space at 50-minute intervals with an adjacent hall serving as a waiting area for incoming patients. Students in the first session were responsible for clinic set-up while students in the final session for that day were responsible for returning the room to classroom mode. One of each student pair met their patient in the parking lot and escorted them into the clinic while the other corresponding student escorted the patient back to their car after the conclusion of the session. Escorting allowed students to assess and treat patients with car transfer problems as well as gain knowledge on car adaptations in some patient's cars.

In addition to six patient sessions, students had one orientation session in which they were given information about their particular patient and introduced to the clinic set-up. Students were responsible to contact their patient prior to the first session and verify the time/date as well as inquire regarding equipment and assistance needs. As needed, students gave their patient reminder calls prior to sessions. Student groups met with the course instructor after conducting the initial examination and discussed their problem list, goals, and plan of care prior to finalizing initial documentation. Subjective-Objective-AssessmentPlan (SOAP) note format was used throughout the experience.

(c) The Internet Journal of Allied Health Sciences and Practice, 2018 
Two classroom sessions were held after the six patient sessions. One session was a grand round patient presentation that included a student generated patient video and summary of their work with the patient. Grand rounds provided an opportunity for student self-reflection in which they reported on what worked well and what did not work well during their patient encounters. This session was a rich discussion of student development and patient diversity. The second classroom session was a peerassessment of all patient documentation. The peer assessment exposed students to peer documentation and yielded rich discussion among multiple small groups.

\section{RESULTS}

The Neuro Clinic was worth $15 \%$ of the Neuro Rehab II course. All students passed this component with grades ranging from $85 \%$ to $100 \%$.

Because of the heterogeneity of volunteer patients' functional abilities, we were unable to quantify progress with a single measurement tool. However, all student documentation indicated improvement in at least one domain in at least one progress note with most students indicating multiple areas of improvement in their discharge summary documentation. Similarly, 100\% of patient volunteers indicated that the clinic benefited them functionally and physically with $86 \%$ indicating strong agreement in their post-session survey.

As shown in Figure 2 and Table 2, patient volunteers consistently gave very positive feedback, with all agreeing and the majority strongly agreeing to all questions, indicating they enjoyed the experience, felt respected, were informed about what to expect, felt acknowledged by the faculty, were comfortable with the environment, and benefited socially, functionally, and physically.

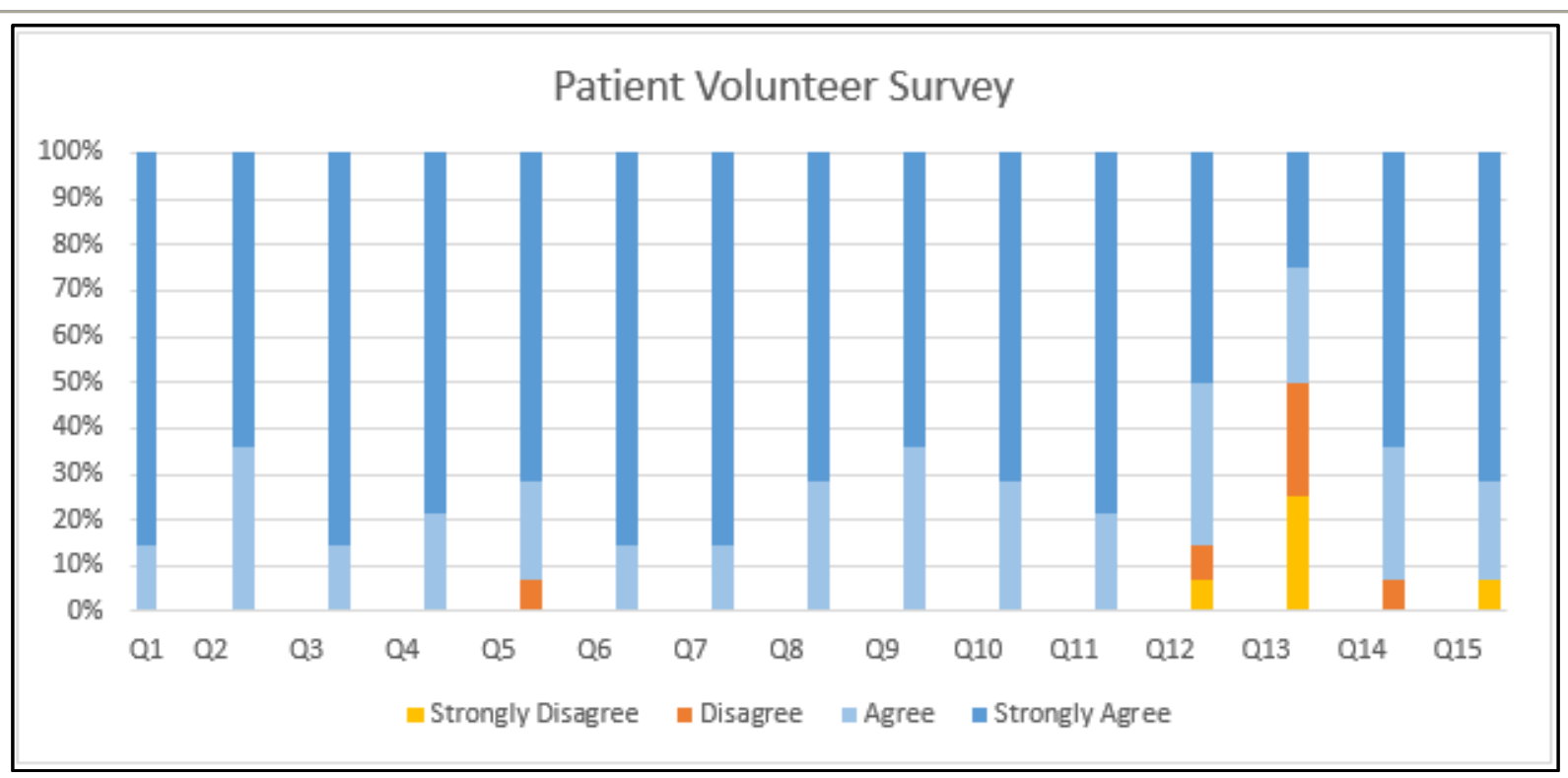

Figure 2 Patient Volunteer Survey Questions

Q1. I enjoyed my experience at the neuro clinic. Q2. I felt informed about what to expect at the neuro clinic. Q3. I felt respected by the students I worked with. Q4. I felt acknowledged by the faculty present at the neuro clinic. Q5. The neuro clinic was beneficial to me socially. Q6. The neuro clinic was beneficial to me functionally. Q7. The neuro clinic was beneficial to me physically. Q8. I felt that the neuro clinic was an opportunity for me to assist the students learning. Q9. Transportation was not an issue for me. Q10. It was not difficult to get to/from the car to the classroom. Q11. The facilities were adequate for this experience. Q12. Once a week for 6 weeks was an adequate time frame. Q13. Changing the clinic to twice a week for 4 weeks would be a better option for me. Q14. I would be willing to return to the neuro clinic next year. Q15. I would be willing to come in for demonstration purposes at other times during the school year

All but one patient volunteer expressed a strong desire to return to future clinics as well being willing to serve as a patient for demonstration purposes in Neuro Rehab I. Volunteer patient opinions varied with regard to thoughts on clinic frequency and duration with $50 \%$ satisfied with the once weekly for six-weeks duration and $14 \%$ preferring a longer duration. The suggestion to change the clinic to twice weekly for four weeks was met with uniform distribution between strongly agree, agree, disagree, and strongly disagree indicating no clear preference regarding scheduling modification. Though often cited as an issue in other 
reports, transportation was not an issue for this group of patient volunteers beyond the attrition of one. ${ }^{9}$ When asked to articulate the best part of the Neuro Clinic, patient volunteer comments included phrases such as, "It has been very enjoyable to meet the students and share my goals and progress and create new goals. I would come do this every day," and "working with knowledgeable, enthusiastic students. A completely positive experience."

Student feedback, as illustrated in Figure 3 and in Table 2, appeared similar to the volunteers and clinician supervisors, though student comments were more in-depth.

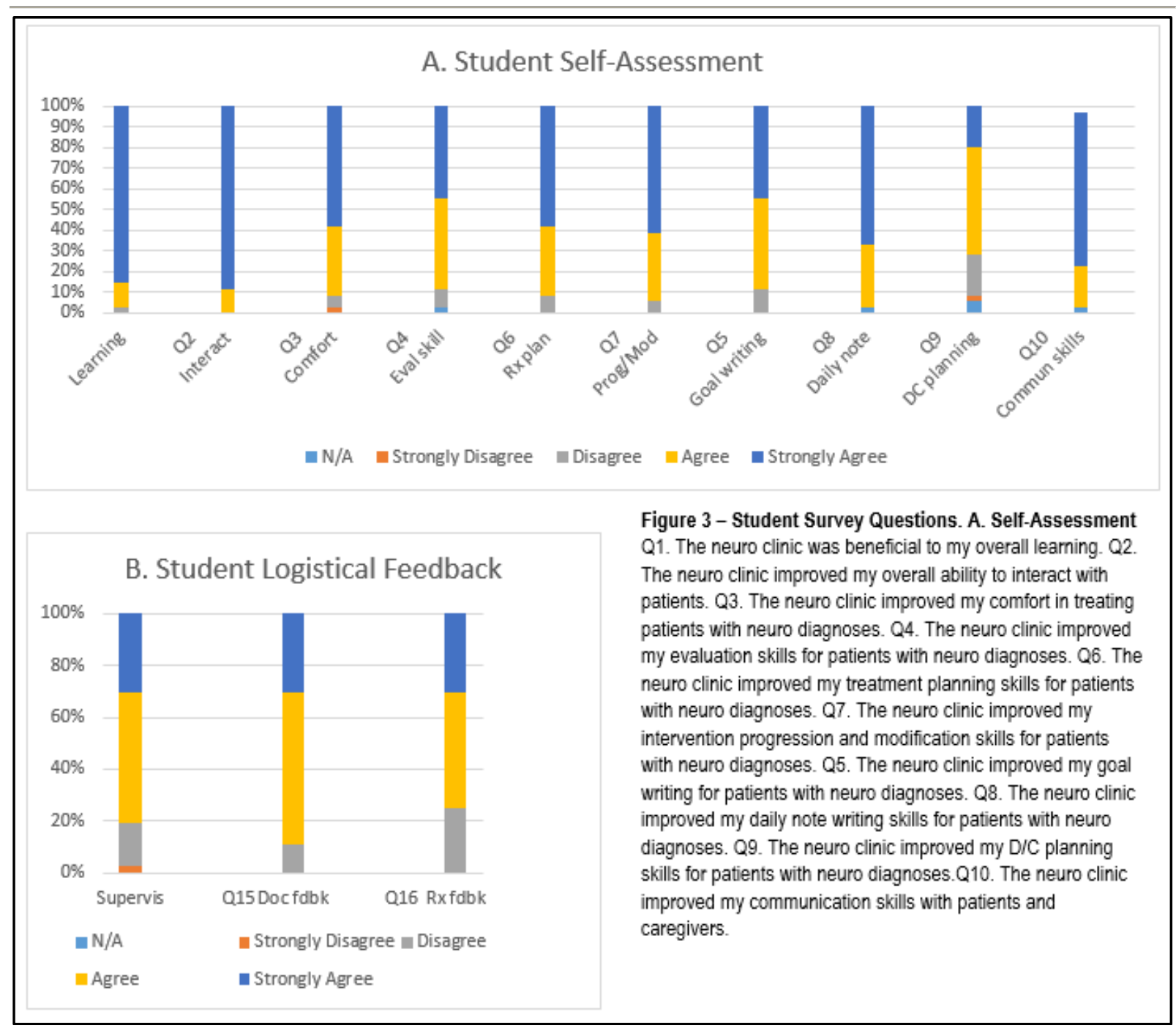

Student survey responses have been separated into two categories: student self-assessment including professional development and skill acquisition and student assessment of clinic logistics, supervision, and feedback. Ninety-seven percent ( $86 \%$ strongly agree, $11 \%$ agree) of the students indicated that the Neuro Clinic was beneficial to their learning and $100 \%$ indicated that it improved their ability to interact with patients and their caregivers. Ninety-one percent noted an increase in their comfort level working with patients with neurological disorders while $93 \%$ indicated an improvement in both their evaluation and intervention skills as well as documentation with this patient population. Comments indicated a desire to watch other groups, however, only $31 \%$ reported a benefit from having other students observe them (e.g. they did not like to be observed by their peers). Fifty-three percent did not take advantage of the opportunity to observe other groups.

Eighty-nine percent of students indicated that feedback regarding documentation was adequate and timely, however $25 \%$ wanted more feedback on interventions. Eighty percent thought the amount of supervision was what they needed. However, 
results were mixed; some thought they received too much supervision and some wanted more. Comments such as "Loved the amount of supervision. It was nice to feel independent without the faculty being over-bearing," and "I appreciated them being around and stepping in when necessary to offer advice and safety monitoring," as well as "They were hands off enough but helped when we sought help," indicated an understanding of our basic philosophy with PEM but it is possible that some students were not ready for this approach. Fifty-six percent of the students indicated a desire to extend the duration and/or the frequency of the Neuro Clinic. The student survey comments seemed to indicate a sense of accomplishment when reflecting on their progress during the clinic when articulating the "best part" as detailed in Table 2.

\section{Table 2 Neuro Clinic Survey Qualitative Comments}

\begin{tabular}{|c|c|c|}
\hline Volunteer Patient & Student & Adjunct Faculty/ Clinician \\
\hline $\begin{array}{l}\text { "It has been very enjoyable to meet } \\
\text { the students and share my goals } \\
\text { and progress and creating new } \\
\text { goals. I would come do this every } \\
\text { day." } \\
\text { "Working with knowledgeable, } \\
\text { enthusiastic students. A completely } \\
\text { positive experience." } \\
\text { "The combination of experience } \\
\text { and enthusiasm was perfect." } \\
\text { "The student therapists aided in my } \\
\text { husband's confidence with balance } \\
\text { and ultimately walking. He has } \\
\text { refined his skill with standing. I } \\
\text { appreciate the home exercises as } \\
\text { well." }\end{array}$ & $\begin{array}{l}\text { "Being able to learn from patients in a } \\
\text { safe environment with good } \\
\text { supervision and guidance. Learning to } \\
\text { adapt treatments based on patients' } \\
\text { needs was very helpful while still in the } \\
\text { classroom with help." } \\
\text { "Being able to interact with real } \\
\text { patients with diagnoses we have } \\
\text { learned so much about. The hands on } \\
\text { experience with real patients was } \\
\text { beneficial and will stick with me } \\
\text { forever." } \\
\text { "Working with patients who had the } \\
\text { disease versus pretending on each } \\
\text { other. It was awesome to do real } \\
\text { interventions with patients who needed } \\
\text { it and to see them improve!" } \\
\text { "Gaining confidence with patient } \\
\text { interaction and documentation. The } \\
\text { clinic really stretched me in several } \\
\text { ways and I feel more prepared for the } \\
\text { clinic because of it." } \\
\text { "Getting to interact with neurological } \\
\text { patients and actually seeing/treating a } \\
\text { specific diagnosis. It is a ton different } \\
\text { than only learning about it in class or } \\
\text { only observing." } \\
\text { "Loved the amount of supervision. It } \\
\text { was nice to feel independent without } \\
\text { the faculty being over-bearing" } \\
\text { "I appreciated them being around and } \\
\text { stepping in when necessary to offer } \\
\text { advice and safety monitoring" } \\
\text { "They were hands off enough but } \\
\text { helped when we sought help" }\end{array}$ & $\begin{array}{l}\text { "I think the neuro clinic is a GREAT } \\
\text { learning opportunity for all students and I } \\
\text { wish that this was offered when I was in } \\
\text { school. I think it allows the students } \\
\text { enough freedom to experiment with } \\
\text { patient interaction/intervention but close } \\
\text { enough supervision so they don't hurt } \\
\text { themselves or the patients." } \\
\text { "The clinic's strengths: Students getting } \\
\text { to interact with actual patients instead of } \\
\text { just hearing about them. Students } \\
\text { developing their own treatment plans and } \\
\text { getting the chance to try them } \\
\text { out. Licensed clinician mentoring to help } \\
\text { students progress or modify treatments. } \\
\text { Family and caregiver interaction and input } \\
\text { into sessions and goals." }\end{array}$ \\
\hline
\end{tabular}

\section{DISCUSSION}


Grading for the Neuro Clinic was purposefully set at $15 \%$ to have a significant impact on the course grade without creating undue student anxiety. One identified value of PEM in our program is the safe environment to try new skills and investigate successful communication strategies. Thus, grading criteria included progressive patient intervention and interaction, timeliness with documentation and clinic time, cooperative work within their group, and a move toward autonomous clinical decision making.

The primary reason for student-expressed dissatisfaction in their survey responses appeared to be in regard to "missing out" on diagnoses other than their assigned patient. However, as indicated in the results section, students did not take full advantage of the opportunity to observe other groups working with patient volunteers with diagnoses different from their assigned case. Likewise, students indicated a dislike of having other students observe them, possibly due to a lack of confidence in their developing skills.

Student surveys also indicated mixed perspectives regarding the amount of faculty supervision and feedback desired. Consistent with active learning processes, faculty/student interaction during treatment sessions was purposely limited and in response to student request. ${ }^{10}$ As long as student/patient volunteer interactions were safe, faculty kept feedback and discussion to a minimum during a treatment session, relying instead on follow-up debriefing with the students apart from the patient volunteer. Better management of student understanding regarding autonomy expectations and faculty mentorship regarding quantity of monitoring may be indicated. These minor issues will be addressed in Next Steps for the next Spring Neuro Clinic.

The PEM facilitates learning consistent with Kolb's experiential learning model by giving the student opportunities to engage in new experiences, reflect on those experiences, interpret the experiences to generate further ideas, and apply newly formed ideas to subsequent patient experiences. ${ }^{10}$ Having multiple treatment sessions with the same student-patient volunteer triad allowed students to sequentially apply and refine new soft skills such as compassion and active listening, as well as hard skills including facilitation techniques and treatment structuring. Pairing students with one patient also facilitated a team approach to patient care and may facilitate reciprocal peer coaching which has been found to influence physical therapy students positively through enhanced clinical competency when compared to individual learning. ${ }^{11,12,13}$

\section{Next Steps}

The Neuro Clinic was expanded and offered as a summer elective to this past year's rising third year students prior to beginning terminal internships. As a progression, students worked individually with patient volunteers instead of in pairs as done in the Spring Neuro Clinic. Held twice a week for four weeks, students worked with two consecutive patient volunteers during two, 1hour sessions, gaining time management experience in handling a consecutive patient load similar to clinical practice. Prior to that day's patient volunteer session, students arrived early to discuss documentation feedback and upcoming treatment strategies with faculty. With complicated logistical scheduling, each student was able to rotate as a "float" at least once during treatment sessions, allowing opportunities to work with a variety of patients as well as to direct ancillary/supportive care. After the two patient sessions, faculty and students debriefed with topics regarding complex patient presentation, intervention progression, patient progress, and issues such as patient non-adherence.

Students shared their reflection on learning moments. In-depth investigation of patient management was student-driven dependent on topics that required further instruction. For example, during the Spring Neuro Clinic, many patient volunteers who were post-stroke were found to have extensive hemiparetic hand dysfunction. Instruction regarding hand rehabilitation was developed and then faculty spent 1:1 time with applicable students facilitating knowledge translation into real-time clinical application. During the Summer Neuro Clinic, several patients with PD were concurrently attending group exercises involving a particular treatment focus. Students were able to obtain resources about this intervention and implement some of these strategies in their plan of care, gaining first-hand experience with a highly used intervention strategy.

Future spring Neuro Clinics will include "Flip Session" scheduling so that students will spend a session with faculty/clinicians doing similar activities piloted in the inaugural summer Neuro Clinic when not working with their patient. At least one flip session will be spent observing another student group. Continued regular written reflections and faculty facilitated discussions will foster student self-assessment regarding professional growth and skill acquisition.

The Neuro Clinic was beneficial from all perspectives and required minimal resources. We anticipate expanding similar opportunities within other clinical courses beyond Neurological Rehabilitation. To that end, an Ortho Clinic was implemented this year consisting of three visits with volunteers with self-identified orthopedic problems working with student pairs throughout the semester. Further implementation for Geriatrics and other patient populations will be finalized at the upcoming annual summer faculty workshop. We anticipate adding a three-session Balance Clinic to our Geriatric course during the same Spring semester,

(C) The Internet Journal of Allied Health Sciences and Practice, 2018 
after the conclusion of the 6-week Neuro Clinic. We are also investigating the logistics of placing $2^{\text {nd }}$ year students as "techs" to assist $3^{\text {rd }}$ year students during the summer elective Neuro Clinic.

\section{Limitations}

Though qualitative data indicates the positive value of the Neuro Clinic, it is unknown at this time if the addition of PEMs within the didactic portion of our curriculum will lead to improved student performance during their terminal internships. Due to the fluidity of any DPT program, it may not be feasible to determine a causal relationship. However, a retrospective study has been planned to compare the Clinical Performance Instrument (CPI) measures on terminal internships from early cohorts who did not have PEM to these newer cohorts who have had the experience.

\section{CONCLUSIONS}

The Neuro Clinic, as all PEMs within the program, was developed as an experiential learning module for students in a clinical professional program to gain skill mastery. By not taking place in a formal clinic, it bypasses many logistical issues including the need for extra time to allow for student travel and variable clinic regulations regarding background checks and immunization requirements mandated by individual facilities. Our PEMs also do not increase the demand on local clinicians to be involved in early student development and allows faculty to be closely involved with matching student clinical skill implementation and progression with concurrent coursework.

This paper describes the implementation of a pilot Neuro Clinic, a strong component of our program's developing PEM embedded within the didactic curriculum. It gives students the opportunity to advance both tangible clinical skills and intangible social and professional skills through actual patient care. It provides faculty the means to mentor and guide students while bridging the gap between didactic education and its clinical application. It also serves the needs of the local community with neurological disorders. This model may be useful to other healthcare programs in their quest to enhance student learning in a way that requires minimal resources and also benefits multiple constituencies.

\section{REFERENCES:}

1. Commission on Accreditation of Physical Therapist Education Website. Available at http://www.capteonline.org/home.aspx. Accessed April 5, 2017.

2. Lekkas P, Larsen T, Jumar S, Grimmer K, Nyland L, et al. No model of clinical education for physiotherapy students is superior to another: a systematic review. Aust J Physiother. 2007;53:19-28. [PMID: 17326735]

3. Engelhard C, McCallum C. A description of current curricular design models used in physical therapy clinical education and their relationship to pass rates on the National Physical Therapy Examination. The Internet Journal of Allied Health Sciences and Practice. 2015;13(4).

4. Wilson A. Integrated clinical experiences in a campus onsite clinic: A self-contained model of physical therapy clinical education. J Allied Health. 2014;12(3);1-17.

5. Hakim EW, Moffat M, Becker E, Bell KA, Manal TJ, et al. Application of education theory and evidence in support of an integrated model of clinical education. J Phys Ther Educ. 2014;28(1):13-21.

6. Mai J, Thiele A, O'Dell B, Kruse B, Vaassen M, et al. Utilization of an integrated clinical experience in a physical therapist education program. J Phys Ther Educ. 2013;27(2):25-32.

7. Kelly SP, King HJ. The community patient resource group: a novel strategy for bringing the clinic to the classroom. $J$ Phys Ther Educ. 2012;26(2):32-40.

8. Rapport MJ, Rodriguez J, Bade M. Use of a community volunteer program to develop value for patient-centered care in physical therapist professional education. J Phys Ther Educ. 2010;24(2):53-9.

9. Doucet B, Seale J. The free post-stroke clinic: a successful teaching and learning model. J Allied Health. 2012;41:1629.

10. Miller AH, Tomlinson S, Tomlinson JD, Readinger J. Addition of a patient examination module to address student preparedness for the first full-time clinical experience. J Phys Ther Educ. 2017;31(2):30-43.

11. Graham CL. Conceptual learning processes in physical therapy students. Phys Ther.1996;76(8):856-65 [PMID: 8710965]

12. Ladyshewsky RK. A quasi-experimental study of the differences in performance and clinical reasoning using individual learning versus reciprocal peer coaching. Physiotherapy Theory Practice. 2002;18:17-31.

13. Gandy J, Jensen G. Group work and reflective practicums in physical therapy education: models for professional behavior development. J Phys Ther Educ.1992;6(1):6-10. 